\title{
Erratum
}

\section{Role of substrate utilization and thermogenesis on body-weight control with particular reference to alcohol}

\author{
By Yves Schutz
}

Volume 59 (2000), Number 4

Figure 1, page 513

Please replace Figure 1 with the following:

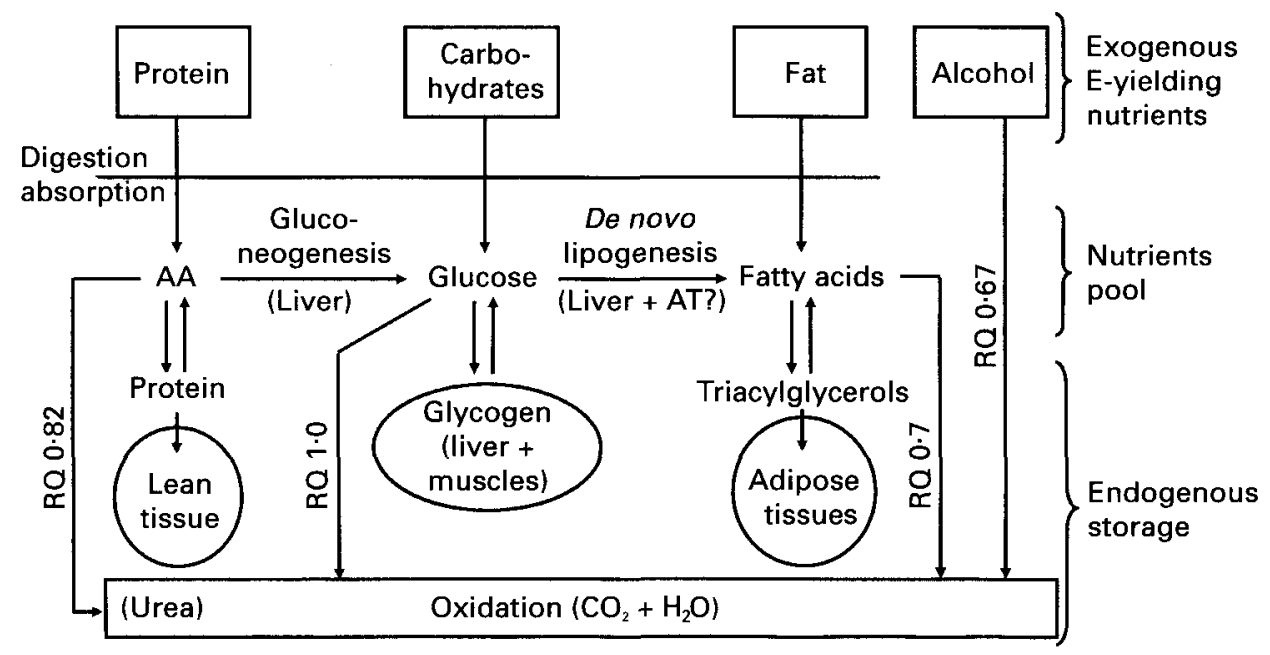

Fig. 1. Schematic simplified overview of the fate of exogenous substrates within the body and their metabolic interconversion by gluconeogenesis and de novo lipogenesis. Endogenous substrates are stored in different body pools, whose size and energy $(E)$ density $(\mathrm{kJ} / \mathrm{g})$ are markedly different among the tissues storing these substrates. Alcohol, distributed in total body water after consumption, does not possess any storing pool as such, and only a limited proportion is converted into fatty acids by de novo lipogenesis. Note that endogenous substrates are constantly turning over at controlled rates which vary according to the nature of substrates, the type of organ and tissues considered and the nature and level of exogenous intake. AA, amino acids; AT, adipose tissue. 